\title{
Dust Capturing Capacity of Woody Plants in Clean Air Zones throughout Taiwan
}

\author{
Yi-Chung Wang ${ }^{1}$ and Bixia Chen ${ }^{2, *(1)}$ \\ 1 Department of Forestry and Nature Conservation, Chinese Culture University, 55, Hwa-Kang Road, \\ Yang-Ming-Shan, Taipei 11114, Taiwan; ycwang@ulive.pccu.edu.tw \\ 2 Faculty of Agriculture, University of the Ryukyus, Okinawa 903-0213, Japan \\ * Correspondence: chenbx@agr.u-ryukyu.ac.jp; Tel.: +81-98-895-8773
}

Citation: Wang, Y.-C.; Chen, B. Dust Capturing Capacity of Woody Plants in Clean Air Zones throughout

Taiwan. Atmosphere 2021, 12, 696. https://doi.org/10.3390/

atmos12060696

\section{Academic Editors:}

Alvaro Enríquez-de-Salamanca and Wan-Yu Liu

Received: 26 April 2021

Accepted: 27 May 2021

Published: 29 May 2021

Publisher's Note: MDPI stays neutral with regard to jurisdictional claims in published maps and institutional affiliations.

Copyright: (c) 2021 by the authors. Licensee MDPI, Basel, Switzerland. This article is an open access article distributed under the terms and conditions of the Creative Commons Attribution (CC BY) license (https:// creativecommons.org/licenses/by/ $4.0 /)$.

\begin{abstract}
To exploit the ability of vegetation to capture particulate matter (dust) from the air and improve air quality, 546 clean air zones (CAZs) consisting of various types of urban green space have been established in Taiwan. This study systematically assessed the pollutant filtering efficiency of tree species planted in these green spaces. This research aims to provide quantitative data on individual trees' dust retention functions for future green space planning in urban areas. Field surveys were conducted in 98 CAZs throughout Taiwan. The vegetation composition of approximately 14,000 woody trees, consisting of 210 species, was surveyed. The vegetation surveyed showed that the dominant species in many CAZs in southern Taiwan were introduced species. The dust capturing capacity of the tree species was found to be positively correlated with leaf size. However, the amount of dust retention was affected mainly by the surface structure and morphological characteristics of the leaves, such as a rough, hairy surface. Among the tree species, Spathodea campanulata, Pterocarpus indicus, and Delonix regia exhibited the best dust capture and retention capacity in southern Taiwan, and Ficus macrocarpa, Alstonia scholaris, and Melia azedarach were the most desirable dust retention species. The results suggest that native evergreen species are suitable for dust retention in urban green spaces.
\end{abstract}

Keywords: air pollutant removal; foliar surface; leaf morphology; dust trapping efficiency; urban green spaces

\section{Introduction}

Air pollution, which consists mainly of nitrogen dioxide $\left(\mathrm{NO}_{2}\right)$ and dust particles, is now the leading environmental cause of human health problems worldwide. Atmospheric dust particles, also called particulate matter (PM), originate from a broad range of sources that include emissions from the combustion of carbon-based fuels (coal, oil, and natural gas) by industry and vehicles; mineral-containing particles from the erosion of agricultural soils, volcanic eruptions, and building activities; and sea-salt particles from bubbles bursting in oceans and along the coast [1]. Dust particles contain a wide variety of pollutants with various chemical compositions; they affect human health by causing respiratory and heart problems resulting from the inhalation of small particles. Green infrastructure (street and park trees, green roofs, tree belts, and other vegetation introduced into the urban landscape) has recently been promoted by policymakers and scientists for air pollution mitigation, e.g., [2-4].

As with other regions worldwide, Taiwan has severe environmental problems, including air and water pollution. Air pollution is most obvious in Taipei, the capital and largest city. It is in a valley surrounded by mountains, and the primary cause of urban air pollution is the large number of vehicles (mostly motorbikes and scooters) [5]. The clean air zone (CAZ) program is intended to improve air quality, enhance the quality of the living environment, increase awareness of ecological and environmental protection, and achieve sustainable use of natural resources. Within the CAZs, vegetation and beautification are enhanced, and cycling lanes and other greening facilities or landscapes are installed [6]. 
Between 1995 and 2019, the total greening area grew to 1,764 ha in cities and counties throughout Taiwan [6]. The CAZs include environmental protection parks (202 ha), barren land greening (897 ha), green boulevards (388 ha), cycling lanes (293 km), 180 campus dust improvement sites (205 ha), and pollution sites, landfill reclamation, and greening and restoration parks (277 ha).

CAZs in Taiwan have been established primarily for air quality purification via dust retention. Numerous studies [7-12] have found that plants or forest belts can effectively intercept dust, filter suspended PM in the air, and reduce air pollution. Acacia confuse and Casuarina equisetifolia presented the highest dust retention capacity in the study of greenbelts in two major highways in Taiwan [10]. Urban forests can significantly contribute to the $\mathrm{PM}_{10}$ removal rate [11].

The foliar surfaces of woody plants are exposed to the surrounding environment and are the main receptors of dust. Plants provide a very large leaf area for absorption, interception, and accumulation of air pollutants, reducing the pollution level in the air [13]. Several previous studies $[9,14,15]$ have reported that the dust retention capacity of tree species varies greatly. Dust retention capacity is related to the nature and shape of leaves; leaves with hairy surfaces have a higher dust retention capacity, whereas those with a smooth surface or a large area with a soft texture have low dust retention capacity. An earlier study [15] that used 15 common species in the Taipei area found that Ficus microcarpa, Nageia nagi, and Tricyrtis formosana had the highest dust deposition rates. The type of falling dust also affects the capture efficiency. For example, cement particles are generally more easily retained than soil particles $[14,16]$. In addition, species composition has an effect on air pollution removal efficiency [17-19]. He et al. [20] found that a $5 \mathrm{~m}$-wide green belt on Sanlihe Road in Beijing filtered and intercepted dust at a dust reduction rate of $85.4 \%$. In addition, the measured dust reduction rate of a $5 \mathrm{~m}$-wide shrub green belt was $22.5 \%$, and the dust reduction rate of a $7 \mathrm{~m}$-wide bush green belt on Beijing Baishiqiao Road was $43.9 \%$.

The dust retention capacity of wet branches is generally greater than that of dry branches [21]. Tsai et al. [22] reported that sprayed branches have the highest dust retention rate for cement particles; they found that dust or cement particles tend to accumulate on the windward side of branches and leaves. The results also show that the dust retention capacity of plants with a small leaf area was higher than that of plants with a larger leaf area. Coniferous trees had more dust than broad-leaved trees [23]; seasonal differences were also observed. Generally, the largest amount of dust is trapped in winter [24], and the chlorophyll content of leaves is inversely proportional to the amount of dust trapped [25].

Since 1995, Taiwan has established 546 CAZs consisting of various types of green space in urban areas; however, the pollutant filtering efficiency of these green spaces has not yet been systematically assessed. The actual tree species composition growing in numerous CAZs is not clear. Some tree species are more pollution-resistant than others. Thus, a thorough field survey is needed to clarify the vegetation composition and explore the dust deposition efficiency of the major tree species in CAZs.

Hence, this study had two research aims. First, it is the first attempt to clarify the dominant tree species and species composition inside the CAZs through field data collection over a wide range throughout Taiwan. The primary purpose is to examine the type of tree species that can be recommended for cultivation in CAZs in terms of dust retention capacity and function of air quality purification. Research on the role of individual trees in urban spaces is still largely lacking [19]. Secondly, this research aims to provide qualitative data on individual trees' dust retention functions for future green space planning in urban areas. This study will also greatly contribute to the knowledge of the dust retention capacity of subtropical and tropical tree species, which are also common in other Asian regions.

\section{Survey Sites and Methodology}

The main island of Taiwan makes up $99 \%$ of the area controlled by the Republic of China (ROC). The ROC, or Taiwan, has an area of $32,260 \mathrm{~km}^{2}$ and a population of 
23.57 million as of August 2020 [26]. There are several peaks above $3500 \mathrm{~m}$, with Yu Shan being the highest at $3952 \mathrm{~m}$, making Taiwan the world's fourth-highest island [27].

Surveys were conducted over two consecutive years, 2010 and 2011. In 2010, 48 CAZs north of Taichung City were selected as sample plots (Figure 1), and 50 CAZs south of Taichung City were selected in 2011 (Figure 1). A full list of selected CAZs is presented in Supplementary Tables S1 and S2. All woody plants with diameters above the root crown or buttress of over $1 \mathrm{~cm}$ in the sample CAZs were surveyed. The diameter at breast height $(\mathrm{DBH})$, tree height, and crown width $(\mathrm{CW})$ were measured with a tape measure. However, herbaceous plants were not measured in this study. Field survey data were used to clarify the dominant tree species in CAZs and the contribution of these green spaces to air pollutant removal and carbon storage. Wang et al. [28] reported the vegetation composition of all the surveyed trees and their carbon storage capacity in 2015. They estimated that an overall amount of 672.20 tons of carbon were stored in the sampling plots, and carbon storage benefits are expected to increase as these trees mature.

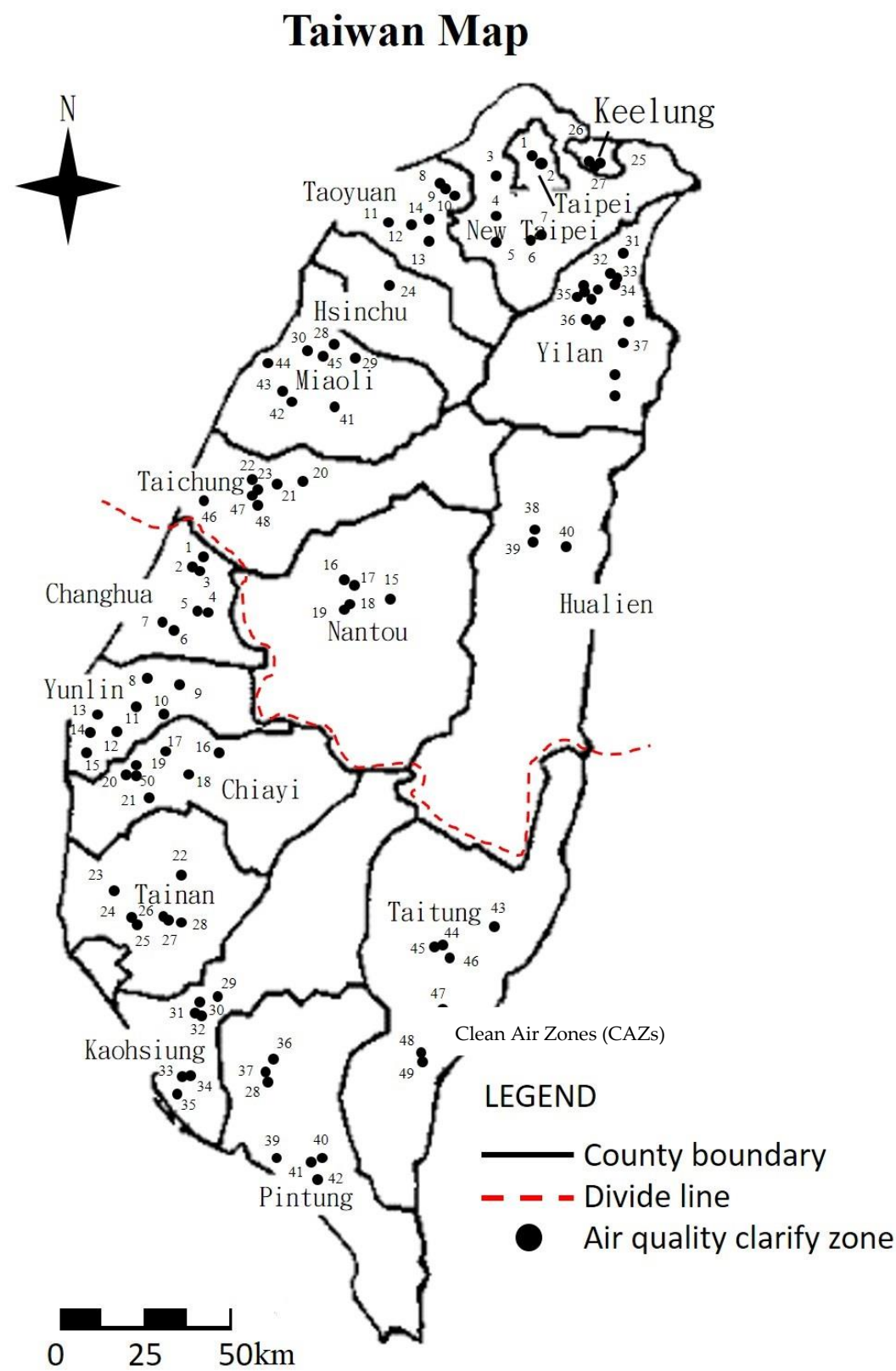

Figure 1. Map of surveyed clean air zones (CAZs). 
The data were split into two regions: the southern part and the central and northern parts. We conducted field surveys over two years, taking into consideration the tree number and plot number. In addition, we expected differences in tree species composition in the northern and southern parts of Taiwan due to its large area. However, no significant difference was found between the two regions; hence, we do not include the discussion of tree species structure differences in this study.

\subsection{Importance Value Index (IVI)}

The importance value index (IVI) of the species was calculated using the method of Curtis and McIntosh [29]. The relative ecological importance of each tree species in each stand was expressed as a summation index (IVI) of the relative frequency (RF), relative density (RD), and relative dominance (RDo) as the following Equation (1):

$$
\mathrm{IVI}=(\mathrm{RF}+\mathrm{RD}+\mathrm{RDo}) / 3 \times 100 \%
$$

where RF, RD, and RDo are defined as

$R F(\%)=($ frequency of species $/$ total frequency of all species $) \times 100 \%$

$\mathrm{RD}(\%)=$ (number of individuals of species/total number of individuals of all species) $\times 100 \%$

RDo $(\%)=($ basal area of a species $/$ total basal area of all species $) \times 100 \%$.

The relative frequency is the frequency of a given species divided by the sum of the frequencies of all species. The relative density is the density of a given species divided by the sum of the densities of all species. The relative dominance is the basal area of a given species divided by the sum of the basal areas of all species. The basal area (BA) is defined as the total cross-sectional area of a single tree at breast height and was estimated using the following Equation (2):

$$
\mathrm{BA}\left(\mathrm{m}^{2}\right)=\left[\pi \times(\mathrm{DBH}(\mathrm{cm}))^{2}\right] / 10,000
$$

where DBH is the diameter at breast height and $\pi=3.14$.

\subsection{Dust Retention Capacity}

The dust retention capacity of trees growing in the CAZs was surveyed to screen the tree species, which is desirable for determining their air purification function. Vegetation survey results were used to calculate the IVI of the woody plant species. Ten dominant woody plant species in the two regions were identified.

Dust retention capacity evaluations consisted of two parts: one involved collecting leaves in the sample CAZs, and the other consisted of buying five seedlings of 10 tree species and placing them to be cultivated in the Beishihu Environmental Protection Park, Neihu Reigion (Gong 103) in Taipei City, for experimental use. However, we could not collect all tree species from one CAZ. The surrounding environment and tree growth conditions may have affected the amount of dust accumulated on the leaves. Hence, we selected sample CAZs that had trees with a rich diversity to obtain all the tree species that we needed for the experiments. Relatively better growing trees were selected for tree leaf sampling. Twenty leaves were collected from each tree. The experiments were repeated three times to sample dust four and seven days after rain. In the Beishihu Environmental Protection Park, five seedling tree leaves were sampled six times, four times at four days after rain, and twice at seven days after rain. Only the leaves that looked healthy and in good condition were collected.

In 2009, trees of the same species and similar ages at the New Taipei City Campus were selected for the dust retention capacity experiments. Trees leaves of Bischofia javanica were collected from sample CAZ No. 6 (see Supplementary Table S1), and the other nine species were collected from sample CAZs No. 1 and 2 (see Supplementary Table S1). 
In 2010, tree leaves were sampled from five CAZs (sample sites No. 2, 5, 6, 7, and 37, see Supplementary Table S2) in the southern part of Taiwan. Tree leaves were sampled 7 days after rain in the southern region, as they were dry in autumn.

The dust load was measured using the formula and methods below (Equation (3)):

$$
\text { Actual dust load }\left(\mathrm{gm}^{-2}\right)=\left[\left(W_{1}-W_{0}\right) \times 10^{3}\right] / A
$$

where $W_{0}$ is the weight of the Petri dish after drying,

$W_{1}$ is the weight of the dried Petri dish after the sampled tree leaves were placed in it and washed with deionized water, and $A$ is the area of the sampled leaf measured using the computer scanner method [22]. After scanning, leaf area was determined using a graphical method, which has also been applied in other studies [12,13]. This method calculates the foliar surface area by counting the total number of dots on each scanned image of the leaves. First, a regular or irregular figure was created by scanning a tree leaf. A figure can be defined as an aggregate of numerous dots at a certain resolution. By counting the number of dots in the figure, its area can be determined.

\subsection{Sedimentation Velocity of Dust}

The speed at which dust particles settle at a constant acceleration in still air is called the sedimentation velocity, defined as the sum of the external forces acting on the dust particles, and is equal to the falling speed of the dust particles at $0 \mathrm{~h}$. The sedimentation velocity can be obtained by dividing the estimated amount of dust by the average atmospheric concentration observed during monitoring.

\section{Results}

\subsection{Vegetation Diversity and Composition}

A total of 14,598 trees consisting of 210 species, 145 genera, and 61 families were measured in 98 sample CAZs. There were 681 trees per hectare on average, and this calculation excluded bicycle lanes (Table 1). In terms of relative density (individual numbers), the most common species was Koelreuteria henryi (1106), accounting for $7.93 \%$. The top 10 species in terms of the number of individual trees comprised $50.18 \%$ of the total number of trees of all species (Table 2). Table 3 lists the tree dimensions measured for the 98 CAZs.

Table 1. Description of areas and number of trees planted in the sample plots.

\begin{tabular}{|c|c|c|c|c|}
\hline Sample Clean Air Zones (CAZs) * & Mean & SD & Min & Max \\
\hline Average area (ha) & 0.573 & 0.728 & 0.002 & 4.8 \\
\hline Average species number & 11 & 11 & 1 & 75 \\
\hline Average tree number/plot & 142 & 165 & 5 & 1181 \\
\hline Average tree number/ha & 681 & 1245 & 15 & 7000 \\
\hline
\end{tabular}

* Cycling lanes have been excluded.

Table 2. Tree species with individual numbers exceeding $5 \%$ of the total number of trees surveyed.

\begin{tabular}{cc}
\hline Species & $\%$ \\
\hline Koelreuteria henryi & 7.93 \\
Cinnamomum burmannii & 6.56 \\
Terminalia boivinii & 6.18 \\
Swietenia macrophylla & 5.37 \\
Cinnamomum camphora & 5.21 \\
Ficus microcarpa & 5.1 \\
\hline
\end{tabular}


Table 3. Tree dimensions of survey plots.

\begin{tabular}{cccc}
\hline Tree Parameters & Total & North Taiwan & South Taiwan \\
\hline Mean tree height & $5.76(1.13-21.00)$ & $5.06(1.3-14.02)$ & $6.44(1.38-21.00)$ \\
(TH) & $15.57(0.5-190)$ & $11.52(0.5-53.8)$ & $18.62(0.6-190)$ \\
Mean DBH $(\mathrm{cm})$ & $3.95(0.1-25.5)$ & $3.15(0.1-16.6)$ & $4.59(0.20-25.50)$ \\
Crown width $(\mathrm{m})$ & $17.57(0.01-510.70)$ & $10.33(0.01-216.42)$ & $23.28(0.03-510.70)$ \\
Crown width $\left(\mathrm{m}^{2}\right)$ & $0.03(0.00-2.84)$ & $0.014(0.00-0.23)$ & $0.05(0.00-2.84)$ \\
Mean Basal Area $\left(\mathrm{m}^{2}\right)$ &
\end{tabular}

Note: numbers in brackets present the minimum and maximum.

This study surveyed 48 air quality purification zones in 10 counties or cities in central and northern Taiwan. In total, 9,761 trees from 168 species were recorded. The maximum number of trees was 1,715 in Hwalian County, and the minimum was 260 in Taipei City. The overall average tree height was $5.06 \mathrm{~m}$, with an average DBH of $11.52 \mathrm{~cm}$. The total wood volume was $767.05 \mathrm{~m}^{3}$.

In the 50 sample plots in southern Taiwan, 4837 trees from 140 species were recorded. The cities with the most trees, largest average $\mathrm{DBH}$, largest average $\mathrm{CW}$, and largest average tree volume were Tainan City (933 trees), Kaoshuing City $(28.64 \mathrm{~cm})$, and Pingtung County $\left(5.65 \mathrm{~m}, 0.4056 \mathrm{~m}^{3}\right)$, respectively.

Table 4 lists the trees with a high IVI in all 98 surveyed CAZs; F. microcarpa showed the highest IVI followed by T. boivinii and K. henryi.

Table 4. Importance Value Index (IVI) of woody plants in the sample plots.

\begin{tabular}{ccccc}
\hline Species & Relative Density & Relative Dominance & Relative Frequency & IVI \\
\hline Ficus microcarpa & 5.1 & 17.71 & 12.14 & 11.65 \\
Terminalia boivinii & 6.1 & 5.58 & 8 & 6.59 \\
Koelreuteria henryi & 7.79 & 3.43 & 8.59 & 5.6 \\
Cinnamomum camphora & 5.21 & 5.28 & 7.05 & 5.51 \\
Cassia fistula & 3.79 & 3.87 & 3.88 & 4.89 \\
Alstonia scholaris & 2.65 & 7.9 & 2.46 & 3.81 \\
Swietenia macrophylla & 5.37 & 3.5 & 2.47 & 3.63 \\
Cinnamomum burmannii & 6.56 & 1.86 & 3.46 & 3.15 \\
Pongamia pinnata & 3.91 & 1.06 & 4.4 & 3.09 \\
Terminalia catappa & 2.45 & 2.41 & & \\
\hline
\end{tabular}

\subsection{Importance Value Index (IVI) in Northern Taiwan}

Table 5 lists the 10 species with the highest IVI in the surveyed CAZs in northern Taiwan. F. microcarpa showed the highest IVI, followed by K. henryi and C. camphora.

Table 5. Important Value Index tree species ranking in north of Taiwan.

\begin{tabular}{ccccc}
\hline Ranking & Species & Stem Nos & Basal Area $\left.\mathbf{( m}^{\mathbf{1}}\right)$ & IVI \\
\hline 1 & Ficus microcarpa & 501 & 46.2 & 10.13 \\
2 & Koelreuteria henryi & 804 & 11.3 & 5.73 \\
3 & Cinnamomum camphora & 534 & 16.0 & 5.5 \\
4 & Swietenia macrophylla & 857 & 12.0 & 5.15 \\
5 & Terminalia boivinii & 625 & 12.3 & 4.99 \\
6 & Cinnamomum burmanii & 891 & 7.6 & 4.78 \\
7 & Palimara alstonia & 234 & 16.0 & 3.83 \\
8 & Pongamia pinnata & 404 & 6.6 & 3.22 \\
9 & Bischofia javanica & 286 & 6.4 & 2.96 \\
10 & Prunus sp & 346 & 1.2 & 2.43 \\
11 & Melia azedarach & 194 & 5.7 & 2.26 \\
\hline
\end{tabular}


Supplementary Table S3 lists the tree species with the highest measured heights among the species with high IVI. In northern Taiwan, F. microcarpa had the highest IVI in the surveyed sites in New Taipei City, Keelung City, Yilan County, Taoyuan County, and Miaoli County. C. camphora had the highest IVI in Taipei City and Hsinchu City. Additionally, S. macrophylla, A. scholaris, and C. burmannii had the highest IVIs in Huanlien City, Miaoli County, and Nantou County, respectively.

Among the 168 species measured, 43 were included among the 10 species with the highest IVI in a city/county. The tree stem number and tree species number varied widely in the sample plots, as the establishment year was different, and some plots had existing vegetation before the plot was established. Supplementary Table S3 shows that F. microcarpa is among the high-IVI tree species in eight cities/counties. K. henryi is among the 10 tree species with the highest IVIs in seven cities/counties. T. boivinii and S. macrophylla are among the 10 tree species with the highest IVIs in six cities/counties. B. javanica was among the 10 tree species with the highest IVIs in five cities/counties.

The IVI is the sum of three indices: relative dominance, relative density, and relative frequency. Thus, a tree species with the highest IVI may not have the largest number of stems. However, high-IVI tree species may contribute significantly to carbon storage in its county/city and may be identified as a favorable tree species in the local region. That is, we can assume that six species with high IVIs, F. microcarpa, C. camphora, T. boivinii, $M$. azedarach, B. javanica, and K. henryi, were the most popular species in the regions north of Taichung. Among these six high-IVI tree species, five were native and one was exotic.

\subsection{Importance Value Index (IVI) in Southern Taiwan}

Table 6 lists the 20 species with the highest IVI in the surveyed CAZs in southern Taiwan. C. fistula showed the highest IVI, followed by F. macrocarpa and T. catppa.

Table 6. Important Value Index tree species ranking in the south of Taiwan.

\begin{tabular}{ccccc}
\hline Ranking & Species & Stem Nos & Basal Area $\left.\mathbf{( c m}^{\mathbf{2}}\right)$ & $\begin{array}{c}\text { Importance Value } \\
\text { Index (IVI) } \\
\mathbf{( \% )}\end{array}$ \\
\hline 1 & Cassia fistula & 410 & $134,685.1$ & 13.36 \\
2 & Ficus microcarpa & 199 & $281,832.7$ & 8.39 \\
3 & Terminalia catappa & 331 & $101,833.1$ & 6.47 \\
4 & Terminalia boivinii & 237 & $121,519.8$ & 5.6 \\
5 & Ficus religiosa & 112 & $253,623.1$ & 5.47 \\
6 & Palimara alstonia & 136 & 186,194 & 4.77 \\
7 & Pterocarpus indicus & 140 & $118,513.1$ & 4.26 \\
8 & Swietenia macrophylla & 301 & $87,600.38$ & 4.24 \\
9 & Koelreuteria henryi & 303 & $43,836.11$ & 3.82 \\
10 & Cinnamomum camphora & 196 & $73,817.32$ & 3.74 \\
11 & Delonix regia & 90 & $58,427.5$ & 2.98 \\
12 & Bischofia javanica & 169 & $53,481.65$ & 2.67 \\
13 & Tabebuia chrysantha & 197 & $27,223.66$ & 2.46 \\
14 & Pongamia pinnata & 155 & $25,234.99$ & 2.08 \\
15 & Spathodea campanulata & 87 & $40,442.15$ & 1.66 \\
16 & Fraxinus formosana & 130 & $23,672.17$ & 1.62 \\
17 & Senna siamea & 30 & $55,315.66$ & 1.33 \\
18 & Cinnamomum burmanii & 132 & $11,150.99$ & 1.17 \\
19 & Ficus elastica & 26 & $36,396.83$ & 1.17 \\
20 & Podocarpus macrophyllus & 41 & $49,516.69$ & \\
\hline
\end{tabular}

Supplementary Table S4 lists the tree species with the highest IVI in each county/city in southern Taiwan. Among the 140 species measured in the regions south of Taichung City, 30 were among those with the 10 highest IVIs in a city/county. A. scholaris had the highest IVI at the surveyed sites in Chiayi and Pingtung. In addition, C. fistula, T. boivinii, F. microcarpa, F. religiosa, and T. catappa had the highest IVIs in Changhua, Yunlin, Tainan, 
Kaohsiung, and Taitung, respectively. Among the 10 tree species with the highest IVIs in the regions south of Taichung City, T. boivinii and C. fistula had the highest IVI values in six cities/counties. S. macrophylla had the highest IVI values among the five cities/counties. These three species are not native, but they were introduced and widely planted, as they are well adapted to the local environment and grow well. K. henryi and C. camphora were among the 10 tree species with the highest IVIs in five cities/counties. The other six species listed as high-IVI species in three cities/counties were D. regia, B. javanica, P. pinnata, T. catappa, A. scholaris, and C. speciosa.

Of the 30 species among the 10 species with the highest IVIs in the regions south of Taichung City, 18 were exotic and the other 12 were native. Many exotic tree species have been introduced and planted in large numbers inside CAZs. Only a few common native species, specifically K. henryi, C. camphora, and F. microcarpa, were found in the CAZs.

\subsection{High Dust Retention Tree Species in Northern Taiwan}

The 10 tree species with the highest IVIs (Table 5) were selected based on a survey of 48 plots in northern Taiwan. An S. macrophylla seedling was not available; thus, it was replaced by an $M$. azedarach seedling for the experiments described below.

Twenty tree leaves were collected from the 10 selected trees, and the foliar surface area was measured (Table 7 and Supplementary Table S5). The average foliar surface areas of F. microcarpa and T. boivinii were the smallest (less than $200 \mathrm{~cm}^{2}$ ) (Table 7). Tree species with compound leaves had the largest foliar surface area. Among them, K. henryi has tripinnately or tetrapinnately compound leaves, and the average foliar surface area was $16,423.9 \mathrm{~cm}^{2}$. M. azedarach has tripinnately compound leaves, but the average foliar surface area was only $5100.00 \mathrm{~cm}^{2}$. This is very similar to that of Pongamia pinnata $\left(5292.4 \mathrm{~cm}^{2}\right)$, which has pinnately compound leaves. B. javanica has ternate compound leaves with an average foliar surface area of $2231.9 \mathrm{~cm}^{2}$.

Table 7. Average dust load and foliar sizes on the sample CAZs in the north part of Taiwan.

\begin{tabular}{|c|c|c|c|c|}
\hline Species & Dust Load (g) & Foliar Size $\left(\mathrm{cm}^{2}\right)$ & $\begin{array}{c}\text { Dust Load } \\
\left(\mathrm{mg} / \mathrm{cm}^{2} / \text { day }\right)\end{array}$ & $\begin{array}{l}\text { Sedimentation } \\
\text { Velocity }(\mathrm{cm} / \mathrm{s})\end{array}$ \\
\hline Ficus microcarpa & $0.05 \pm 0.04$ & $161.8 \pm 69.1$ & $0.29 \pm 0.25$ & $5.53 \pm 0.13$ \\
\hline Prunus sp & $0.06 \pm 0.04$ & $1043.2 \pm 425.6$ & $0.06 \pm 0.03$ & $0.77 \pm 0.03$ \\
\hline Cinnamomum campora & $0.02 \pm 0.05$ & $273.5 \pm 125.8$ & $0.07 \pm 0.7$ & $4.12 \pm 0.05$ \\
\hline Cinnamomum burmanii & $0.05 \pm 0.06$ & $445.8 \pm 217.3$ & $0.10 \pm 0.11$ & $2.00 \pm 0.06$ \\
\hline Bischofia javanica & $0.09 \pm 0.19$ & $2231.9 \pm 1021.0$ & $0.04 \pm 0.08$ & $1.25 \pm 0.02$ \\
\hline Melia azedarach & $1.33 \pm 0.94$ & $5100.0 \pm 2079.2$ & $0.27 \pm 0.19$ & $3.57 \pm 0.17$ \\
\hline Pongamia pinnata & $0.19 \pm 0.21$ & $5292.4 \pm 2295.3$ & $0.04 \pm 0.03$ & $0.75 \pm 0.02$ \\
\hline Alstonia scholaris & $0.08 \pm 0.06$ & $894.1 \pm 593.4$ & $0.10 \pm 0.05$ & $1.62 \pm 0.03$ \\
\hline Terminalia boivinii & $0.02 \pm 0.05$ & $175.0 \pm 75.4$ & $0.12 \pm 0.24$ & $3.36 \pm 0.07$ \\
\hline Koelreuteria henryi & $2.54 \pm 1.18$ & $16,423.9 \pm 8022.7$ & $0.16 \pm 0.07$ & $2.46 \pm 0.03$ \\
\hline
\end{tabular}

The amount of dust on each leaf was positively correlated with the foliar surface area (Table 7). K. henryi had the highest average dust load (2.54 g), followed by M. azedarach (1.33 g), P. pinnata (0.19 g), and B. javanica (0.09 g). By contrast, C. camphora and T. boivinii had an average dust load of $0.02 \mathrm{~g}$, which is attributed to the small foliar surface areas. Regarding the dust capturing amount in terms of every $\mathrm{cm}^{2}$ of tree leaf area, F. macrocarpa ranked the highest, followed by M. azedarach and K. henryi (see Table 7).

The foliar surface area of the seedlings was relatively smaller than that of the sampled leaves from the CAZs. The dust retention capacity of seedling leaves was similar to that of the samples from the CAZs. K. henryi and M. azedarach retained the highest amount of dust, measured to be $4.49 \mathrm{~g}$ and $3.13 \mathrm{~g}$, respectively (Supplementary Table S5).

Foliar surface characteristics also affected the amount of dust retained. M. azedarach and $K$. henryi have rough leaf surfaces, which contribute to their high dust capturing capacity. The average leaf area of F. microcarpa was the smallest $\left(161.8 \mathrm{~cm}^{2}\right)$, which was 
much smaller than that of P. sp. $\left(1043.2 \mathrm{~cm}^{2}\right)$. However, the two species retained a similar amount of dust $(0.05 \mathrm{~g}$ and $0.06 \mathrm{~g}$, respectively). The relatively high dust retention capacity was attributed to the waxy foliar surface of F. microcarpa. P. pinnata and B. javanica were ranked the lowest.

The sedimentation velocity of the sampled tree species was determined by dividing the amount of dust retention by the monitoring data of the EPA air quality index. The monitoring data for Neihu District, Taipei City, were available for nine species. Only the samples of B. javanica were collected from Butouqiao CAZ, New Taipei City. Thus, the monitoring data of the EPA air quality index in Tamsui District, which is close to New Taipei City, were used for calculation.

The dust sedimentation velocity of the tree species at the sample sites followed the same trend as the dust retention capacity. F. microcarpa and M. azedarach had the highest dust load capacity and sedimentation velocity. In contrast, the estimated sedimentation velocity of $P$. pinnat $a$ was the lowest. The results of the dust sedimentation experiments using seedling leaves were similar to those of the sampled plots. M. azedarach had the highest sedimentation velocity, followed by $K$. henryi and T. boivinii. In contrast, B. javanica and P. pinnata had the lowest sedimentation rates.

\subsection{High Dust Retention Tree Species in Southern Taiwan}

Among the 140 surveyed species in southern Taiwan, 20 had an IVI higher than $1 \%$. C. fistula $(13.36 \%)$ had the highest IVI, followed by F. microcarpa $(8.39 \%)$ and T. catappa $(6.47 \%)$. The others had IVIs of less than $6 \%$. Ten species were selected (Table 6) according to their IVIs, excluding those used in the previous year's experiment in the northern area, and were used for further dust retention experiments.

F. religiosa and T. catappa have single leaves. T. chrysantha has palmately compound leaves, and $D$. regia has bipinnately compound leaves. The other six species have pinnately compound leaves. The average foliar surface area is presented in Table 8. C. fistula and S. campanulata had the largest leaf areas of 261.2 and $242.6 \mathrm{~cm}^{2}$, respectively, because their compound leaves consist of many leaflets. F. formosana had the smallest leaf area $\left(25.5 \mathrm{~cm}^{2}\right)$. D. regia had a large leaf area $\left(176.2 \mathrm{~cm}^{2}\right)$, which was attributed to the large number of leaflets.

Table 8. Average dust load and foliar sizes in sample CAZs the south part of Taiwan.

\begin{tabular}{|c|c|c|c|c|}
\hline Species & Dust Load (g) & Foliar Size $\left(\mathrm{cm}^{2}\right)$ & $\begin{array}{l}\text { Dust Load } \\
\left(\mathrm{mg} / \mathrm{cm}^{2} / \text { day) }\right.\end{array}$ & $\begin{array}{l}\text { Sedimentation } \\
\text { Velocity }(\mathrm{cm} / \mathrm{s})\end{array}$ \\
\hline Swietenia macropnylla & $0.028 \pm 0.016$ & $156.4 \pm 11.3$ & $0.026 \pm 0.014$ & $0.37 \pm 0.20$ \\
\hline Delonix regia & $0.076 \pm 0.044$ & $176.2 \pm 82.6$ & $0.087 \pm 0.061$ & $1.44 \pm 1.25$ \\
\hline Cassia fistula & $0.039 \pm 0.010$ & $261.2 \pm 10.2$ & $0.021 \pm 0.006$ & $0.32 \pm 0.08$ \\
\hline Tabebuia chrysantha & $0.074 \pm 0.048$ & $242.6 \pm 15.9$ & $0.045 \pm 0.031$ & $0.87 \pm 0.84$ \\
\hline Fraxinus formosana & $0.002 \pm 0.001$ & $25.5 \pm 0.2$ & $0.013 \pm 0.006$ & $0.22 \pm 0.11$ \\
\hline Pterocarpus indicus & $0.086 \pm 0.075$ & $125.7 \pm 11.0$ & $0.100 \pm 0.086$ & $1.77 \pm 1.80$ \\
\hline Ficus religiosa & $0.012 \pm 0.008$ & $86.0 \pm 9.2$ & $0.020 \pm 0.015$ & $0.29 \pm 0.24$ \\
\hline Spathodea campanulata & $0.013 \pm 0.005$ & $83.9 \pm 18.0$ & $0.024 \pm 0.013$ & $0.40 \pm 0.22$ \\
\hline Senna siamea & $0.010 \pm 0.007$ & $63.4 \pm 15.9$ & $0.021 \pm 0.015$ & $0.25 \pm 0.16$ \\
\hline Terminalia catappa & $0.022 \pm 0.002$ & $92.2 \pm 6.8$ & $0.034 \pm 0.005$ & $0.52 \pm 0.05$ \\
\hline
\end{tabular}

The amount of dust retention was almost always positively correlated with foliar surface size (Table 8). F. formosana and S. siamea had the smallest average leaf size, and their leaves intercepted the least dust. Among the tree species with pinnately compound leaves, $P$. indicus accumulated the most dust, although its average leaf size was not the largest. C. fistula had the largest leaf size; however, its dust capturing capacity ranked 7th among the 10 species. The inconsistent relationship between leaf size and dust-capturing capacity may be explained by foliar surface characteristics. For example, C. fistula has a glabrous leaf surface, whereas $P$. indicus has a rough surface, which contributes to its 
greater dust-capturing capacity. T. chrysantha also has a rough surface leaf; hence, it was ranked third in terms of its dust capturing capability.

Experiments on seedling leaves also showed that leaf size was positively correlated with dust capturing capacity (Supplementary Table S6). The S. macrophylla seedlings had the largest leaves $\left(157.3 \mathrm{~cm}^{2}\right)$, followed by T. chrysantha and C. fistula. F. religiosa and F. formosana were measured to have the smallest leaf size, and they trapped the least dust per leaf on average. The dust capture efficiency ranking is presented in Table 8. The ranking in the seedling experiments was similar to that of the samples from the CAZs.

C. fistula and F. formosana have glabrous leaves; hence, their dust-capturing capacity was low. In addition, the blade and petiole of $F$. religiosa leaves were similar in length. Therefore, the leaves swing violently when the wind blows; as a result, the amount of absorbed dust was low. S. campanulata has finely pubescent leaflets, and the amount of dust it accumulated was disproportional to the leaf size. Dust collection by newly sprouted leaves among the $T$. chrysantha samples may explain why less dust than expected was captured by the leaves. The data were collected in fall, and T. chrysantha is a deciduous species; thus, we were able to collect only young leaves instead of mature leaves.

The foliar surface area of the seedlings was relatively smaller than that of the sampled leaves from CAZs. The dust retention capacity of seedling leaves was similar to that of the samples from the CAZs. S. macropnlla and S. campanulate retained the highest amount of dust, with values of 0.026 and $0.023 \mathrm{~g}$, respectively (Supplementary Table S6).

\section{Discussion}

A woody vegetation composition survey in the CAZs revealed that these urban greens/forests accommodate a high diversity of tree species. However, many exotic species have been planted in large numbers inside CAZs, especially in the southern part of Taiwan. In comparison, native species found to be dominant in the CAZs were usually limited to a few species of F. macrocarpa, C. campora, and K. henryi. The exotic species have been widely criticized for their susceptibility to typhoons, and in August 2015, Typhoon Soudelor caused tremendous damage to 16,000 trees in Taipei City, which split or collapsed [30]. Native species are a better choice for greening species, as they exhibit better pest and disease resistance because they are adapted to the climate and environment. Native species are commonly deep-rooted and resilient in regions with frequent typhoons. It is recommended that more native tree species should be cultivated in CAZs to improve biodiversity, as well as forests resilient to the local climate.

It was found that the dust interception and retention capacity of a tree species were related to leaf size and foliar surface characteristics. Furthermore, foliar surface characteristics such as toughness, hairiness, and leaf cuticle characteristics make a greater contribution than leaf size to the dust-capturing capacity of a species. This result is consistent with previous findings that dust accumulation depends on the morphological characteristics of plants [24,31-33]. A long petiole also decreases the dust capturing efficiency, as the leaves swing vigorously when the wind blows. The complex tree leaf structure of pinnately, tripinnately, or tetrapinnately compound leaves also contributes to the dust retention efficiency [34].

Among the dominant tree species in CAZs in northern Taiwan, K. henryi and $M$. azedarach had the highest dust capture and retention capacity, which was attributed to the rough foliar surface. F. microcarpa was also highly efficient at capturing and retaining dust particles owing to its waxy foliar surface, despite its small leaves. Hence, K. henryi, M. azedarach, and F. macrocarpa are recommended as desirable dust capturing species in the CAZS.

Among the dominant tree species in southern Taiwan, three species, S. campanulate, P. indicus, and D. regia, had high dust retention capacity and can be recommended as the most desirable species in terms of air purification.

Deciduous tree species are not recommended as dust-capturing species. Our study found that $T$. boivinii showed a high dust load capacity; however, we do not recommend 
it as a dust control species as it is a deciduous species. In addition, Prunus sp. is not recommended as a dust control tree species because it is deciduous. Moreover, $B$. javanica and P. pinnata are not recommended because of their low sedimentation velocities. The filtering effects of evergreen trees are reportedly better than those of deciduous species [35].

\section{Conclusions}

CAZs contain a wide range of tree species, including old-growth native species and many newly introduced species. Our survey concluded that trees planted in the CAZs effectively retained some of the PM in the air. As dust control species, we strongly recommend evergreen tree species with high dust capture and retention efficiency. Among the species with high IVI at the survey sites, three species, $K$. henryi, M. azedarach, and F. microcarpa, are strongly recommended, followed by A. scholaris, C. camphora, and C. burmannii.

In future research, other ecosystem services provided by trees in the CAZs should be assessed, as it has been established that they enhance the quality of life, improve landscape amenity, and protect the environment. Moreover, future research and urban green space planning should also consider the danger caused by trees, such as the emission of biogenic volatile organic compounds (BVOCs) associated with ozone formation [36]. It was found that coniferous and broad-leaved species were predominantly monoterpene and isoprene emitters [37]. Some tree species are the most potent allergen sources and cause a trade-off between the benefits and problems of tree species.

The quantitative data of dust amount captured by individual species can serve as the database for screening the best choice of urban forestry. This database will be expected to contribute to the knowledge of tree species in the tropics and subtropics.

Supplementary Materials: The following are available online at https:/ / www.mdpi.com/article/10 .3390/atmos12060696/s1, Table S1 Surveyed Clean Air Zones (CAZs) in north of Taiwan; Table S2 Surveyed Clean Air Zones (CAZs) in south of Taiwan; Table S3 Important Value Index tree species ranking in north of Taiwan; Table S4 Important Value Index tree species ranking in south of Taiwan; Table S5 Average dust load and foliar sizes on the seedlings in the north part of Taiwan; Table S6 Average dust load and foliar sizes of the seedlings in the south part of Taiwan.

Author Contributions: Conceptualization, Y.-C.W. and B.C.; methodology, Y.-C.W.; software, Y.-C.W.; validation, Y.-C.W. and B.C.; formal analysis, B.C.; investigation, Y.-C.W.; resources, Y.-C.W.; data curation, B.C.; writing-original draft preparation, Y.-C.W., and B.C.; writing-review and editing, Y.-C.W. and B.C.; visualization, B.C.; supervision, Y.-C.W.; project administration, Y.-C.W.; funding acquisition, Y.-C.W. All authors have read and agreed to the published version of the manuscript.

Funding: This research was funded by the National Science Council and Environmental Protection Administration, Taiwan, ROC [grant number: NSC98-EPA-M-009-001 and NSC 100-EPA-F-010-001].

Institutional Review Board Statement: Not applicable.

Informed Consent Statement: Not applicable.

Data Availability Statement: Not applicable.

Acknowledgments: We are thankful for all students and young collogues who have contributed to our field data collection and primary data analysis.

Conflicts of Interest: The authors declare no conflict of interest.

\section{References}

1. United Kingdom Air Pollution Information System (APIS). Dust. Available online: http://www.apis.ac.uk/overview/pollutants / overview_particles.htm (accessed on 26 September 2020).

2. Berardi, U.; Ghaffarian Hoseini, A.H.; Hoseini, G. State-of-the-art analysis of the environmental benefits of green roofs. J. Appl. Energy 2013, 115, 411-428.

3. Beatley, T. Handbook of Biophilic City Planning and Design; Island Press: Washington, DC, USA, 2016.

4. Nowak, D.J.; Hirabayashi, S.; Bodine, A.; Hoehna, R. Modeled PM2.5 removal by trees in ten US cities and associated health effects. Environ. Pollut. 2013, 178, 395-402. [CrossRef] 
5. United States Department of Energy (2003) Taiwan: Environmental Issues. Country Analysis Brief-Taiwan. October 2003. Archived from the Original on 7 October 2006. Available online: https://web.archive.org/web/20061007165852/http://www. eia.doe.gov/emeu/cabs/taiwanenv.html (accessed on 25 September 2020).

6. Environmental Protection Administration (EPA), ROC (Taiwan). Clean Air Zone. Available online: https://www.epa.gov.tw / eng/3707030B84708564 (accessed on 25 September 2020).

7. Yin, S.; Cai, J.; Chen, L.P.; Shen, Z.; Zou, X.D.; Wu, D.; Wang, W. Effects of vegetation status in urban green spaces on particle removal in a street canyon atmosphere. Acta Ecol. Sin. 2007, 27, 4590-4595.

8. Lipfert, F.W.; Wyzga, R.E.; Baty, L.D.; Miller, J.P. Traffic density as a surrogate measure of environmental exposures in studies of air pollution health effects: Long-term mortality in a cohort of US veterans. Atmos. Environ. 2006, 40, 154-169. [CrossRef]

9. Chen, F.; Zhou, Z.X.; Xiao, R.B. Estimation of ecosystem services of urban green-land in industrial zones: A case study on green-land in the workshop zones of the Wuhan lron and Steel Company. Acta Ecol. Sin. 2006, 26, 2230-2236.

10. Wang, Y. Carbon sequestration and foliar dust retention by woody plants in the greenbelts along two major Taiwan highways. Ann. Appl. Biol. 2011, 159, 244-251. [CrossRef]

11. Baro, F.; Chaparro, L.; Gomez-Baggethun, E.G.; Langemeyer, J.; Nowark, D.J.; Terradas, J. Contribution of ecosystem services to air quality and climate change mitigation polices: The case of urban forests in Barcelona, Spain. AMBIO 2014, 43, 466-479. [CrossRef]

12. Chaudhary, I.J.; Rathore, D. Dust pollution: Its removal and effect on foliage physiology of urban trees. Sustain. Cities Soc. 2019, 51, 101696. [CrossRef]

13. Escobedo, F.J.; Wagner, J.E.; Nowak, D.J. Analyzing the cost effectiveness of Santiago, Chile's policy of using urban forest to improve air quality. J. Environ. Manag. 2008, 86, 148-157. [CrossRef] [PubMed]

14. Wang, C. Studies on the Dust Catching Ability and the Properties of Dust-Tolerance of Green Plants. Master's Thesis, National Taiwan University Graduate Institute of Horticulture, Taipei City, Taiwan, 1998. (In Chinese)

15. Chang, Y. Study on Detecting and Cleaning the Atmospheric Particulates by Plants. Master's Thesis, National Taiwan University, Graduate Institute of Plant Pathology and Microbiology, Taipei City, Taiwan, 2007. (In Chinese) [CrossRef]

16. Honda, H. Fundamental study on the planting and space effect in the public nuisance prevention in the city: III. Dust Catching Ability of Plant Foliage. Tech. Bull. Fac. Hortic. Chiba Univ. 2005, 22, 81-88.

17. Li, J.; Feng, C.; Duan, J.; Xiu, Y. The efficiency of green spaces to purify air and design principles of pollution prevention greening. In Research on Greening Environmental Effects; Feng, C., Ed.; China Environmental Science Press: Beijing, China, 1992; pp. 41-54. (In Chinese)

18. Kaur, S.; Nieuwenhuisen, M.J.; Colvile, R.N. Pedestrain exposure to air pollution along a major road in Central London, UK. Atmos. Environ. 2005, 39, 7307-7320. [CrossRef]

19. Yang, J.; McBrid, J.; Zhon, J.X.; Sun, Z. The urban forest in Beijing and its role in air pollution reduction. Urban For. Urban Green. 2005, 3, 65-78. [CrossRef]

20. He, L.; Liu, Y.; Feng, C. The dust capturing effects of urban green spaces. In Research on Greening Environmental Effects; Feng, C., Ed.; China Environmental Science Press: Beijing, China, 1992; pp. 71-76. (In Chinese)

21. Tsai, C. Deposition and Removal of Air Pollution Particles on Plant Surfaces. Master's Thesis, National Taiwan University Graduate Institute of Forestry, Taipei City, Taiwan, 2004. (In Chinese) [CrossRef]

22. Tsai, C.; Sun, E.; Wang, Y. Evaluation of dust deposition rates on dry and wet leaves and stems of common trees in Taipei. $J$. Environ. Prot. 2005, 28, 39-52. (In Chinese)

23. Neofytou, P.; Venetsanos, A.G.; Rafailisdis, S.; Bartzis, J.G. Numerical investigation of the pollution dispersion in an urban street canyon. Environ. Model. Softw. 2006, 21, 525-531. [CrossRef]

24. Prajapati, S.K.; Pandey, S.K.; Tripathi, B.D. Monitoring of vehicles derived particulates using magnetic properties of leaves. Environ. Monit. Assess 2006, 120, 169-175. [CrossRef]

25. Zhong, K.; Kang, Y.M.; Wang, C.P. Relationship between street corner design in urban plan and urban air environment. China Environ. Sci. 2001, 21, 460-463.

26. Department of Household Registration, Ministry of the Interior, ROC (Taiwan). Household Registration Statistics Data Analysis in August 2020. Available online: https: / / www.ris.gov.tw /app/en/2121?sn=20253026 (accessed on 25 September 2020).

27. US. Central Intelligence Agency the World Facebook: Taiwan. 2021. Available online: https://www.cia.gov/the-world-factbook/ countries/taiwan/ (accessed on 12 May 2021).

28. Wang, Y.; Liu, W.; Ko, S.; Lin, J. Tree species diversity and carbon storage in Air Quality Enhancement Zones in Taiwan. Aerosol Air Qual. Res. 2015, 15, 1291-1299. [CrossRef]

29. Curtis, J.T.; McIntosh, R.P. An Upland Forest Continuum in the Prairie-Forest Border Region of Wisconsin. Ecology 1951, 32, 476-496. [CrossRef]

30. Yen, H.; Wu, S. The Liberty Times. The combination of politics and business results in planting the wrong trees: Taiwan's land ecology has collapsed. Lib. Times 2015. Available online: https://news.ltn.com.tw/news/life/breakingnews/1408789 (accessed on 26 April 2021). (In Chinese)

31. Rai, P.K.; Panda, L.L.S. Leaf dust deposition and its impact on biochemical aspect of some roadside plants of Aizawl, Mizoram, North East India. Int. Res. J. Environ. Sci. 2014, 3, 14-19. 
32. Chen, X.; Zhou, Z.; Teng, M.; Wang, P.; Zhou, L. Accumulation of three different sizes of particulate matter on plant leaf surfaces: Effect on leaf traits. Arch. Biol. Sci. Belgrade 2015, 67, 1257-1267. [CrossRef]

33. Sharma, B.; Sharma, S.; Bhardwaj, S.K. Plant-pollutant interactions with a special mention of dust accumulation by plants-A review. Nat. Environ. Pollut. Technol. 2017, 16, 375-384.

34. Ingold, C.T. Fungal Spores; Clarendon Press: Oxford, UK, 1971; p. 215238.

35. Dochinger, L.S. Miscellaneous Publication No.1230. USDA For. Serv. Up. Darby 1973, 22.

36. Willis, K.J.; Petrokofsky, G. The natural capital of city tree-City trees can help to reduce pollution and improve human health. Science 2017, 356, 374-376. [CrossRef]

37. Yaman, B.; Aydin, Y.M.; Koca, H.; Dasdemir, O.; Kara, M.; Altiok, H.; Dumanoglu, Y.; Bayram, A.; Tolunay, D.; Odabasi, M.; et al. Biogenic volatile organic compound (BVOC) emissions from various endemic tree species in Turkey. Aerosol Air Qual. Res. 2015, 15, 341-356. [CrossRef] 